\title{
Models ANd The Semantic And Pragmatic VIEWS OF THEORIES
}

\author{
LUIZ HENRIQUE DUTRA \\ Federal University of Santa Catarina, and $\mathrm{CNPq}$
}

\begin{abstract}
This paper aims at discussing from the point of view of a pragmatic stance the concept of model as an abstract replica. According to this view, scientific models are abstract structures different from set-theoretic models. The view of models argued for here stems from the conceptions of some important philosophers of science who elaborated on the notion of model, such as Suppe, Cartwright, Hempel, and Nagel. Differently from all those authors, however, the conception of model argued for here is typically pragmatic, not semantic, i.e. it has not to do with the interpretation of scientific theories, but with the explanation and construction of given circumstances (both abstract and concrete), from the point of view of the theory.
\end{abstract}

\section{Introduction}

From a pragmatic point of view the role played by models in the scientific enterprise is more important than the use of models to interpret scientific theories. However, models we talk about as to the scientific practice are not the same models we talk about as to the interpretation of theories, even though these two kinds of models may be related to each other. In this paper a pragmatic view of scientific theories will be argued for and compared with the semantic view of theories, held by Bas van Fraassen, Frederick Suppe and others.

The semantic view of scientific theories is one of the tenets of Bas van Fraassen's constructive empiricism. According to him, the overall idea of this approach is that scientific theories are not to be interpreted in terms of axiomatic, deductive systems, but as families of models. In The Scientific Image van Fraassen comments on the notion of model he employs, he gives some examples, and uses that notion to define empirical adequacy. He comments also on some of these points in Laws and Symmetry. ${ }^{1}$ At first glance, van Fraassen is referring to what may be called semantic models, i.e. the kind of set-theoretic structures used to interpret formalized first order languages, such as Patrick Suppes does. In fact, however, van Fraassen draws on E. W. Beth's conception of a state space. Even though the concept of model is central in his approach, van Fraassen doesn't comment on it 
extensively. More extensive comments on the concept of model may be found, on the other hand, in Frederick Suppe's works.

Frederick Suppe also adopts the semantic view of theories. However, he conceives of scientific models as the kind of structure he calls physical systems. Physical systems are abstract replicas (his term), and they are quite different from settheoretic structures. In this paper I will draw on Suppe's notion of an abstract replica in order to characterize scientific models as abstract structures used by working scientists not only to interpret their theories but, most importantly, to construct them as well. There are some similarities between Suppe's conception of scientific models and Nancy Cartwright's, even if she doesn't adopt the semantic view of theories. I will also draw on Nancy Cartwright's conception of models as simulacra and blueprints for nomological machines. ${ }^{2}$ Finally, in order to explain my conception of scientific models as abstract replicas, I will comment on Carl Hempel's distinction between analogical and nomic models. Differently from all such authors, however, I adopt a pragmatic stance as to models and scientific theories.

\section{Frederick Suppe on models and physical systems}

Frederick Suppe uses different alternative terms in connection with the term 'model'. In his now classic The Structure of Scientific Theories, as he comments on Ernest Nagel's and Mary Hesse's ideas of models Suppe says that one of the main types of models is what he calls mathematical model, i.e. "a semantic interpretation for a theory such that the theorems of the theory are true under the interpretation." (Suppe 1977b, p. 96-7.) Suppe recognizes that the term he uses may lead to confusions, since one might take scientific models as mathematical structures. Indeed, mathematical models in Suppe's sense are set-theoretic structures, which are sometimes also called semantic models.

Suppe compares mathematical models with what he calls iconic models. According to him, iconic models are the kind of models Nagel and Hesse talk about. In his other book, The Semantic Conception of Theories and Scientific Realism, Suppe comments on models again, in many passages, which do not always shed much light on the subject. For instance, in chapter 5, as he discusses the role played by theoretic laws (i.e. generalizations about the entities scientific theories talk about, not just empirical generalizations), Suppe says that a theory "models the behaviors of possible systems in its intended scope by determining sequences of state occurrences which correspond to the behaviors of all possible such sys-

Principia, 12(1) (2008), pp. 73-86. 
tems." (Suppe 1989, p. 153.) But Suppe affirms in a footnote that he is "using the term 'model' to mean iconic model — an entity which is structurally similar to the entities in some class." (1989, p. 167, n. 3.)

In another passage in that same book Suppe says that, according to the semantic view, "scientific theories are relational systems functioning as iconic models which characterize all the possible changes of state the systems within their scope could undergo under idealized circumstances." (1989, p. 155.) In that same part of the book, Suppe comments on the difference between an idealization and an abstraction, which I will consider later in this paper (Suppe 1989, p. 167). Now, the way Suppe tries to explain what he names iconic model i.e. what characterizes possible changes of state - doesn't correspond either to the common notion of an iconic model or to the notion which in Hesse's and Nagel's texts would be associated with this term. Hesse, Nagel and others (myself included) refer to iconic models as physical replicas or simplified physical representations (such as scale models and diagrams). In this case, iconic models are quite different from abstract models - for example, a frictionless inclined plane. But Suppe, in passages such as the one just cited above in this paragraph, seems to use the term 'iconic model' to refer to this kind of abstract structure, and not to physical representations of certain systems.

In other passages of his book, Suppe comments on the interpretation of theories according to the semantic view and criticizes the axiomatic view. He makes clear that scientific theories cannot be identified with their linguistic formulations, but that they must be interpreted as "abstract structures serving as models to sets of interpreted sentences that constitute the linguistic formulations [of such theories]. These structures are metamathematical models of their linguistic formulations..." (1989, p. 82). However, the term Suppe uses here doesn't shed light either on his conception of models, if compared with the examples he gives (such as physical systems, for instance, the frictionless inclined plane). Even if Suppe's use of the term 'metamathematical model' could suggest an approximation with set-theoretic or semantic models, I think this isn't the case, since, on the other hand, he holds also that the models of a scientific theory "describe the behavior of abstract systems, known as physical systems," he says $(1989$, p. 83).

Such physical systems, says Suppe as well, result from the abstraction from actual phenomena and may idealize the phenomena in various ways; for example, particles may be taken as dimensionless point-masses. So, says Suppe, such systems are "abstract replicas of actual phenomena, being what the phenomena would have been if no other parameters exerted an influence [upon them]." (1989, p. 83) In other terms, as Suppe himself puts it as well in that same page of the

Principia, 12(1) (2008), pp. 73-86. 
book, such physical systems are "replicas of phenomena on which certain idealized conditions [...] are imposed, which actual phenomena cannot ever meet." In this sense, Suppe also says, "the behavior of a physical system is its change in states over time, and this can be viewed as its history." (1989, p. 83)

Viewed this way, abstract physical systems resemble Beth's notion of phase state (or state space), which is assumed by van Fraassen in his version of the semantic view. A phase space is a space "upon which certain configurations (e.g. trajectories, branching trees, subspaces) have been imposed by the laws of the theory."' However, Suppe makes clear that he doesn't construe scientific theories the same way as van Fraassen and Beth but as "canonical iconic models of theories." (1989, p. 113; cf. also Suppe 1977b, p. 227.) Now, Suppe's insistence in using the term 'iconic model' doesn't help to understand his main idea. It is clear that what he has in mind is the connection between the models of a theory and the laws that describe possible states of a system, whose behavior is explained by the theory by means of its models. And this conception of models has nothing to do with iconic models, but with what I will call later in this paper nomological models.

The interesting idea I'd like to drawn upon is Suppe's conception of scientific models as abstract physical systems. It is this very idea that can be merged with other ones, of other authors, to be examined in the remainder of this paper. In order to retain the core of Suppe's conception I propose to drop the term 'iconic model' as he uses it, and to reserve it just for physical representations of certain systems that physically resemble such systems (scale models and diagrams), as the term is currently used. So the models Suppe talks about are not really (in the sense just explained) iconic, but abstract.

\section{Cartwright on simulacra and blueprints for nomological machines}

Initially, Nancy Cartwright accounts for scientific models as simulacra. According to the Oxford English Dictionary she cites, a simulacrum is "something having merely the form or appearance of a certain thing, without possessing its substance or proper qualities." (Cartwright 1983, pp. 152-3.) In this sense, says Cartwright, a model is a work of fiction, possessing some of the properties of the objects modeled, but possessing also other properties that are merely properties of convenience.

So, some of a model's properties are "pure fictions" that are not even approached in reality. Such properties are introduced to bring the object modeled

Principia, 12(1) (2008), pp. 73-86. 
into the range of a mathematical theory, and the success of this kind of strategy depends on how precisely a model can replicate real situations. (Cf. Cartwright 1983, p. 153.) The idea that a model is a replica is also central on this view.

In addition, Cartwright says that differently from other authors who discuss models, such as Mary Hesse, ${ }^{4}$ she is concerned with a more general kind of model. Cartwright writes as follows:

I think that a model — a specially prepared, usually fictional description of the system under study — is employed whenever a mathematical theory is applied to reality, and I use the word 'model' deliberately to suggest the failure of exact correspondence which simulacra share with [...] Hesse's analogical models..." (1983, pp. 158-9)

Cartwright makes also clear that her conception of scientific models is different from those held by the supporters of the semantic view of theories. In this connection she writes as follows:

In short, on the simulacrum account the model is the theory of the phenomenon. This sounds very much like the semantic view of theories, developed by Suppes and Sneed and van Fraassen. But the emphasis is quite different. At this stage I think the formal set-theoretic apparatus would obscure rather than clarify my central points. (1983, p. 159)

In more recent works Cartwright gives another account of scientific models. First, she distinguishes interpretative models (set-theoretic or semantic models) from representative models, which she wants to focus on. A representative model, says Cartwright, is what is needed when we want to represent what happens in certain specific circumstances. In this connection she says that a theory gives us

purely abstract relations between abstract concepts. For the most part it tells us the capacities or natures of systems that fall under these concepts $[\ldots]$, no specific behavior is fixed until those systems are located in very specific kinds of situations. When we want to represent what happens in these situations we will need to go beyond theory and build a model, a representative model. And [...] if what happens in the situation modeled is regular and repeatable, these representative models will look very much like blueprints for nomological machines. (Cartwright 1999a, p. 180; cf. also Cartwright 1999b, pp. 241ff.)

According to Cartwright, nomological machines are certain arrangements of parts or components such that certain laws are exhibited, such as the solar system. But many nomological machines are engineered by us, obviously,

Principia, 12(1) (2008), pp. 73-86. 
such as laboratory experiments (cf. Cartwright 1999a, p. 49). In addition, says Cartwright, it is the models that give us a set of components and their arrangement. She writes as follows:

When we attend to the workings of the mathematical sciences, like physics and economics, we find the important role models play in our accounts of what happens; and when we study these models carefully we find that they provide precisely the kind of information I identify in my characterization of a nomological machine. (1999a, p. 53)

Now, by my lights, Cartwright's most interesting idea about models is that they are what we have to follow - i.e. blueprints - if we want to construct nomological machines. (Cf. 1999a, pp. 58-9.) This is the operational or instrumental aspect of her view of models. Even if Cartwright argues for a realistic view of capacities in her book The Dappled World as well as in her previous book, Nature's Capacities, ${ }^{5}$ her conception of scientific models is clearly anti-realistic. What models help us to do is to make sense of certain "pockets of precise order," she says, in the world described by the exact sciences, like physics and economics. (Cartwright 1999a, p. 57.)

Cartwright's representative models are not physical replicas or representations, obviously. The ways the simulacra or the blueprints for nomological machines she talks about represent certain systems are also abstract, not physical. I'll leave this point without discussion here, for it could be possible to ask how scientific models represent certain systems without resorting to physical media. And a cognitive answer could be in order here, as argues Ronald Giere (Giere 1988 and 1992). I don't adopt a cognitive approach as to the way scientific models as abstract replicas represent certain systems. Rather, I center my analysis of this matter on abstract replicas as such, as Cartwright herself does.

\section{Hempel on nomic models}

Carl Hempel is the last philosopher whose ideas I'd like to comment on in order to argue for a pragmatic conception of scientific models. Hempel distinguishes analogical models from nomic models. Analogical models have a didactic and heuristic role to play in science, but they are not essential to the formulation and application of theories. Analogical models are, for example, scale models, used for modeling by analogy just the arrangement of parts of the object modeled. Hempel's analogical models are the iconic models I've been talking about, not in Suppe's but in the current sense of the term.

Principia, 12(1) (2008), pp. 73-86. 
In their turn, nomic models have to do with the behavior of certain systems. Consider the model that represents an electric current in a network of wires in analogy with the flow of a liquid through a network of pipes. In this case, the most important, says Hempel, is that the analogy "consists in an isomorphism between the laws governing the two processes" (Hempel 1977, p. 251). The point here is that the electric current behaves "as if" it were a liquid flowing through pipes. Examples of scientific models like that, says Hempel, are the Bohr model of the hydrogen atom and the structure ascribed to DNA molecules. (Hempel 1977, p. 252.) One of the systems is a model for the other.

It's true that Hempel still talks about nomic models in terms of analogy. But analogy here refers to behavior, not structure. In this case, two systems are compared as to their similar behaviors, and not as to their possible physical constitution or structure. It is true that similarity of structure may suggest a certain similarity as to behavior, but the similar behaviors of the systems are the feature to be considered here.

In the text I've been commenting on, Hempel discusses Nagel's conception of model, which has been criticized by Suppe. Hempel's conception of nomic models, in opposition to analogical models (or iconic models), resembles what Nagel calls formal analogies, in opposition to substantive analogies. In substantive analogies, according to Nagel, "a system of elements possessing certain already familiar properties, assumed to be related in known ways as stated in a set of laws for the system, is taken as a model for the construction of a theory for some second system." (1963, p. 110.) In this sense, says Nagel, the word 'model' stands for "a set of visualizable macroscopic objects." (1963, p. 110.) Nagel is here referring to the kind of model I've been naming iconic models, such as scale models.

On the other hand, in formal analogies, the system used as a model exhibits some already known abstract pattern of relations. Consider the concept of mass (Nagel's example) in classical and relativistic mechanics. Relativistic mass, says Nagel, has been introduced in analogy with the classical concept of mass. According to Nagel, this example "illustrates how the mathematical formalism of one theory can serve as a model for the construction of another theory with a more inclusive scope of application than the original one." (Nagel 1963, p. 111.) The point here is that there is "an abstract pattern of relations" associated with one theory (Newtonian mechanics) that has been used for the development of the new theory (relativistic mechanics), says Nagel (1963, p. 113). Analogy here is just analogy of behavior, not structure.

Nagel's substantive analogies and Hempel's analogical models, as I said above, are iconic models. Such models may play important roles in science, but, according Principia, 12(1) (2008), pp. 73-86. 
to Hempel, the role played by nomic models are much more important. Nomic models have to do with the behaviors of the systems being compared and with the laws that describe their similar behaviors, given some restrictive conditions, namely, what we have in the comparison between the concepts belonging to classical and relativistic mechanics, according to Nagel.

Thus, it seems to me that there is a convergence between Cartwright's notion of a model as the blueprint for a nomological machine and Hempel's notion of nomic models. I will call this kind of scientific model - which is not iconic but behavioral - nomological model. My nomological models are as abstract as Suppe's physical systems and Cartwright's blueprints for nomological machines. Scientific models are abstract nomological models, which, in their turn, may be interpreted in terms of set-theoretic models. In addition, if set-theoretic models are abstract, mathematical entities, nomological or scientific models are another sort of abstract entities, similar to linguistic entities (words, sentences, etc.), for instance.

\section{Models as abstract replicas}

Some philosophers distinguish between idealization and abstraction. Nancy Cartwright for instance, says that in an idealization we rearrange the features or specific properties of a concrete system or object, before trying to writing down a law for it (1989, ch. 5). Cartwright says that the paradigm case is the frictionless plane. We start with a particular plane or with a class of planes, and we ignore interferences due to friction. By contrast, she says, in an abstraction

we consider the causal factors out of context all together. It is not a matter of changing any particular features or properties, but rather of subtracting, not only the concrete circumstances but even the material in which the cause is embedded and all that follows from that. (Cartwright 1989, p. 187)

Margaret Morrison maintains also the same distinction argued for by Cartwright (cf. Morrison 1999).

An alternative distinction is presented by Suppe (cf. 1989, ch. 3), according to whom in an idealization we have an impossible causal situation; and, by contrast, in an abstraction we have a causally possible situation. According to classical mechanics, for example, it is possible that a given system, such as an inclined plane, be (partially) isolated from the interference of other systems (depending on experimental control). In this case, we have an abstraction. But as to

Principia, 12(1) (2008), pp. 73-86. 
the ideal inclined plane there is no friction, no air resistance, no electromagnetic forces acting upon it, etc., i.e. no interference of other systems. However, Suppe himself says that such a distinction may not be considered. (Suppe 1989, p. 167.) To the effect of interpreting scientific theories according to the semantic view the distinction is not important, since the sequences of states determined by a scientific theory

indicate what the behaviors of the possible systems within the theory's scope would be were it the case that only the parameters of the theory exerted a non-negligible influence on those behaviors. That is, the theory characterizes what the possible behaviors of systems are under idealized circumstances wherein the values of the parameters do not depend on any outside influences, and thus relates counterfactually to many actual systems within its intended scope. (Suppe 1989, pp. 153-4.)

It seems to me that Suppe's distinction is much closer to our use of the terms 'ideal' and 'abstract' in current ordinary language and in current scientific parlance. Suppe's distinction between abstraction and idealization is a matter of degree, since we can have many different degrees of abstraction, beginning with the study of concrete systems and going up to the formulation of ideal ones. As for Cartwright's distinction, it is not very clear that when we think of a frictionless plane we are just rearranging its properties. It seems to me that what we are doing is subtracting one of the features of concrete planes, namely friction.

Anyway, other different distinctions between idealization and abstraction may be proposed, and either argued for or criticized. As for me, I'd say that an idealization is the maximum degree of abstraction, i.e. the circumstances in which there are no interferences of other systems acting upon the system under study. This is why in an idealization, as says Suppe, we have an impossible situation. Thus, for our interpretative purposes, it is more convenient to talk about abstractions. In other words, in this sense of the term 'abstraction', scientific models don't represent concrete but abstract systems.

Here we are trapped in a metaphysical puzzling dispute, that one about the difference between abstract and concrete things. The way out of this kind of endless philosophical discussion seems to me to be the following: for the time being we can say that a model as an abstraction is the description of circumstances not given in space and time (or in space-time, as some would prefer to say), even though space and time mightn't be today accepted by professional physicists as the criteria for identifying concrete objects. ${ }^{6}$

Principia, 12(1) (2008), pp. 73-86. 
Thus, if only systems in space and time are actual systems in this sense, then scientific models are ideal or abstract. This doesn't mean that the systems corresponding to scientific models are not real in a certain philosophically defensible meaning of the term. This is another philosophical debate we can avoid - just for the time being - since the point here is to emphasize that scientific models don't describe systems that we can observe or construct, but systems similar to those ones we observe and construct, which, in their turn, are located in space and time.

Scientific models, as well as set-theoretic models, are not only representations, but also abstractions in the sense of the term I discussed above. There is an important difference, however, between these two kinds of abstractions. Set-theoretic models represent certain systems extensionally, while scientific or nomological models, in their turn, represent the very same systems intensionally. That is to say, scientific models describe the properties of a given system and correlate them even in the absence of an extensional interpretation of the terms employed by a scientific theory. For instance, in the nomological sentence ' $f=m a$ ' that describes an aspect of the behavior of physical systems according to classical mechanics, ' $m$ ' stands for mass, but the term 'mass' is not extensionally interpreted.

By contrast, a set-theoretic or semantic model (for a first order language used to communicate that theory) gives us the individuals belonging to the set that defines a predicate. But the scientific or nomological model just describes the possible situations to which the formula ' $f=m a$ ' apply. In one of the current senses of the term 'abstraction', a nomological model for a given system is more abstract than the corresponding set-theoretic model. And, in its turn, the set-theoretical model may represent the more abstract, nomological model as well.

This conception of scientific models asks for a pragmatic stance. The focus is not anymore on theories, but on the scientific practice. Models as abstract replicas are the result of our investigative action. To abstract is to act upon certain representations in order to produce new ones. Our investigative operation of abstracting might well be viewed as a kind of mental process, if we are interested in cognitive processes, as does Ronald Giere for instance, as I said above. (Giere 1988 and 1992.) But abstracting is a kind of scientific procedure, in the first place. It is a pattern of our scientific behavior. To build models is to abstract from known circumstances into new ways of viewing phenomena. Our modeling activity is certainly guided by theories, but scientific models are not just a way of interpreting theories.

Principia, 12(1) (2008), pp. 73-86. 
To take abstractions as cognitive processes, as does Giere, is to give them an explanation. But before we give an explanation for our scientific practices in terms of more abstract, unobservable entities and processes, as cognitive psychologists and philosophers do, we can consider modeling as an element of scientific practice as such. In this case, we just describe modeling as a pattern of scientific behavior. My point here is to call attention upon the description of scientific practices and behaviors, and according to such a description of what I propose to call the pragmatics of inquiry, modeling is a typical scientific kind of behavior. The analysis of the pragmatics of inquiry restricts itself entirely to the realm of observable, overt behaviors of scientists.

According to this view, scientific models play a two-fold role in the scientific enterprise. First, models as abstract replicas are intellectual tools we use to act upon representations. We start from the concepts given by a certain theory and we use a model to understand the circumstances in which the laws related to the theory apply. This is obviously a sort of interpretation of the theory, but it isn't the same kind of interpretation given by means of a set-theoretic model. In this case, we have what Cartwright calls a representative model.

In the second place, models as abstract replicas are scientific tools we use to make experiments and observations. Here we start with a blueprint for a nomological machine, and we try to find actual circumstances with which the idealized setting described by the model can be compared. If the nomological machine isn't real, and if it is a situation we can construct, then we use the model as a blueprint for constructing such nomological machine.

In both cases scientific models enable us to deal with theory, to have a deeper understanding of its concepts and laws, and eventually to reformulate the theory itself. Thus, viewed this way, scientific models are the most important tools of scientific investigation. They are not to be replaced by other kinds of structures, such as set-theoretic models, since their roles couldn't be played by these other kinds of structures.

In addition, scientific models as abstract replicas are a large class of structures. There are small and large models, as well as static and dynamic models. All such models may also be related with each other. Some models are parts of larger models, and other ones are models of models. However, according to the pragmatic stance here adopted, we can't identify all kinds of scientific models a priori. It is the scientific practice within real, historical research programs that can disclose all sorts of models as abstract replicas and describe its properties and relations. All we know about them up to now stems from the philosophical analysis of circumstances of scientific investigation described by the history of science.

Principia, 12(1) (2008), pp. 73-86. 
History of science gives us elements for understanding past scientific behaviors. Written research reports (such as scientific reports proper, published papers and books) are the best source of information about past scientific practice. But more important than the study of such kinds of documents about past scientific research is the analysis of present observable scientific behaviors. And in this connection the scientist's verbal behavior is a primary source of information, including published material. The activity of modeling, as I briefly described it above, is reported by scientists themselves as something they do with models. As typical scientific behavior, dealing with models is a way for trying to bring together theory and fact. ${ }^{7}$

\section{References}

Cartwright, N. 1983. How the Laws of Physics Lie. Oxford: Clarendon Press.

—. 1989. Nature's Capacities and Their Measurement. Oxford: Clarendon Press.

—. 1999a. The Dappled World. A Study of the Boundaries of Science. Cambridge: Cambridge University Press.

—. 1999b. Models and the Limits of Theory: Quantum Hamiltonians and the BCS Models of Superconductivity. In Morgan and Morrison 1999: 241-81.

Giere, R. N. 1988. Explaining Science. A Cognitive Approach. Chicago and London: The University of Chicago Press.

—. 1992. Cognitive Models of Science. Minneapolis: University of Minnesota Press.

—. 2001. Theories. In Newton-Smith 2001: 515-524.

Hempel, C. G. 1977. Formulation and Formalization of Scientific Theories. A SummaryAbstract. In Suppe 1977a: 244-65.

Hesse, M. B. 1966. Models and Analogies in Science. Notre Dame, Indiana: University of Notre Dame Press.

Morgan, M. S. and Morrison, M. 1999 (eds.), Models as Mediators. Perspectives on Natural and Social Science. Cambridge: Cambridge University Press.

Morrison, M. 1999. Models as Autonomous Agents. In Morgan e Morrison 1999: 38-65.

Moulines, C. U. 2006. La Philosophie des Sciences. Fin XIXe/Début XXIe Siècle. L'Invention d'une Discipline. Paris: Éditions Rue D'Ulm.

Nagel, E. 1961. The Structure of Science. Problems in the Logic of Scientific Explanation. New York and Burlingame: Harcourt, Brace \& World, Inc.

Newton-Smith, W. H. (ed.) 2001. A Companion to the Philosophy of Science. Oxford: Blackwell.

Suppe, F. (ed.) 1977a. The Structure of Scientific Theories. Urbana and Chicago: University of Illinois Press.

Principia, 12(1) (2008), pp. 73-86. 
— 1977b. The Search for Philosophic Understanding of Scientific Theories. In Suppe 1977a: 1-241.

—. 1989. The Semantic Conception of Theories and Scientific Realism. Urbana and Chicago: University of Illinois Press.

van Fraassen, B. C. 1980. The Scientific Image. Oxford: Clarendon.

-. 1989. Laws and Symmetry. Oxford: Clarendon.

\title{
Keywords
}

Models, semantic view, pragmatic view, abstract entities.

Luiz Henrique Dutra

Philosophy Department, Federal University of Santa Catarina

and

Brazilian National Council for Scientific and Technological Development

P. O. Box 5176

88040-970 Florianópolis

Brazil

lhdutra@cfh.ufsc.br

http://www.cfh.ufsc.br/ lhdutra

\begin{abstract}
Resumo
Este artigo procura discutir de um ponto de vista pragmático o conceito de modelo como réplica abstrata. De acordo com esta concepção, os modelos científicos são estruturas abstratas diferentes de modelos conjuntistas. A concepção dos modelos defendida aqui provém das concepções de alguns filósofos da ciência importantes que fizeram elaborações sobre a noção de modelo, tais como Suppe, Cartwright, Hempel e Nagel. Deferentemente de todos esses autores, contudo, a concepção de modelo a ser defendida aqui é tipicamente pragmática, e não semântica, isto é, não tem a ver com a interpretação de teorias científicas, mas com a explicação e a construção de determinadas circunstâncias (tanto abstratas quanto teóricas), do ponto de vista de uma teoria.
\end{abstract}

\section{Palavras-chave}

Modelos, concepção semântica, concepção pragmática, entidades abstratas.

Principia, 12(1) (2008), pp. 73-86. 


\section{Notes}

${ }^{1}$ Cf. van Fraassen 1980 and 1989, respectively.

${ }^{2}$ Cf. respectively Cartwright 1983 and 1999. Even though Cartwright doesn't adopt the semantic view of theories, her work is included by Moulines (2006) among the different versions of what he calls the modelistic approaches of post-positivistic philosophy of science.

${ }^{3}$ Suppe 1989, p. 113. Cf. also van Fraassen 1980, pp. 67 and 196-7, Giere 2001, p. 519, and Moulines 2006 p. 124.

${ }^{4}$ Hesse is primarily concerned with models as analogies, that is to say, with the comparison of a certain structure or system with another.

${ }^{5}$ Respectively, Cartwright 1999a and 1989.

${ }^{6}$ Harvey Brown raised this question during the discussion of my paper at the Principia symposium. But, provisionally, we may continue to talk about abstract — as opposed to concrete - objects as the ones not found in space-time. Philosophically speaking, this distinction allows one to talk about models as abstract replicas (not physical, concrete copies, nor scale models) of certain systems.

${ }^{7}$ A first version of this paper has been presented at the Fifth Principia International Symposium, Florianópolis, Brazil, on August 2007. The paper has been rewritten during my sojourn in Paris, France, as a visiting researcher at IHPST (Institut d'histoire et de philosophie des sciences et des techniques, University of Paris I-Panthéon Sorbonne) during January 2008. My research bas been sponsored by the Brazilian National Council for Scientific and Technological Development, CNPq. I'd like to thank both these institutions and my colleagues at IHPST for their support as well as my colleagues in Florianópolis (Federal University of Santa Catarina).

Principia, 12(1) (2008), pp. 73-86. 